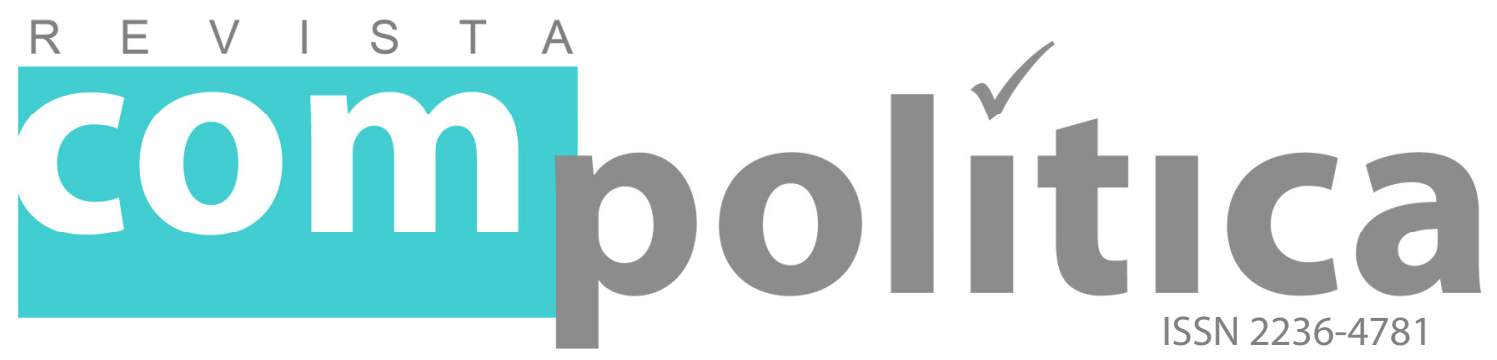

ROSSETTO, Graça

Doutoranda em Comunicação e Cultura Contemporâneas pela UFBA, bolsista CNPq.

<graca_rossetto@yahoo.com.br>

\title{
CARREIRO, Rodrigo
}

Doutoranda em Comunicação e Cultura Contemporâneas pela UFBA. <rodrigocarreiro@gmail.com>

\section{ALMADA, Maria Paula}

Doutoranda em Comunicação e Cultura Contemporâneas pela UFBA.

<mariapaula.almada@gmail.com>

\section{Twitter e comunicação política: limites e possibilidades}

\section{RESUMO}

O cenário de ampliação de fronteiras tecnológicas para comunicação impõe promessas e desafios à democracia e à política. Prova disso são as mídias sociais, aqui exemplificados pelo Twitter; que, criado em 2006, já é objeto de pesquisa recorrente. Com base nisso, aqui se propõe um estudo exploratório da recente bibliografia brasileira que trata dos usos e potencialidades do Twitter em interface com a comunicação política. O objetivo é mapear tendências e caminhos de investigação, além de delinear os limites de um campo de pesquisa proeminente. Dessa pesquisa se adianta a existência de 50 estudos, sendo a maioria relatos a respeito da utilização do Twitter nas eleições. Destaca-se também o enriquecimento do seu uso ocasionado pela evolução da ferramenta e seu domínio pelos atores políticos.

Palavras-chaves: Twitter, comunicação política, democracia.

\section{ABSTRACT}

The scenario of expanding technological boundaries to communication imposes promises and challenges to democracy and politics. The social media are a proof of this, and here they are exemplified by Twitter, created in 2006 and already a great subject of research. Based on that, we propose an exploratory study of the recent Brazilian literature that addresses the uses and potential of Twitter in political communication. The goal is to map trends and avenues of research and outlines the limits of a prominent search field. This research found 50 studies about the theme, most of them are reports about the use of Twitter in the elections. Also noteworthy is the enrichment of their use caused by the evolution of the tool and its domain by political actors.

Keywords: Twitter, political communication, democracy. 


\section{Twitter e comunicação política: limites e possibilidades}

\section{[Twitter and political communication: limits and possibilities]}

ROSSETTO, Graça

CARREIRO, Rodrigo

ALMADA, Maria Paula

\section{Introdução}

$\mathrm{N}$

a relação entre os campos da comunicação e da política, indo além das definições, é preciso entender a comunicação como um processo que penetra a política enquanto atividade (GOMES, 2004). Buscando compreender as implicações do fenômeno da comunicação de massa para a política, incluindo seu desenvolvimento tecnológico e consequentes desdobramentos sociais, chega-se à conclusão de que a interface entre esses campos distintos ilumina aspectos importantes da relação entre media e democracia.

As características mais interativas oferecidas pela Web $2.0^{1}$ aparecem como rica fonte de recursos que podem ser postos a serviço da comunicação política (PARLAMEE; BICHARD, 2012; AGGIO, 2010). A ação de compartilhamento no Facebook ou a replicação de mensagens no Twitter, por exemplo, revelam um alargamento nas relações de contato, partilha ou interação entre os usuários, independente de seu pertencimento a uma mesma rede social.

\footnotetext{
${ }^{1}$ Web 2.0 consiste em uma expressão utilizada para caracterizar a chamada segunda etapa da geração de serviços na Web, cujo principal objetivo é ampliar as formas de produzir a compartilhar informações on-line (O'Reilly, 2005).
} 
Nesse sentido, o Twitter parece especialmente interessante por se mostrar como um local de ressonância de temas e discussões políticas que são divulgadas pelos mais diversos meios de comunicação. Parece ser nas mídias sociais que as questões políticas repercutem e ganham diferentes desdobramentos; o que se acredita ter efeito na opinião dos indivíduos a respeito dos temas em discussão.

De acordo com Parlamee e Bichard (2012), a utilização deste microblog apresenta três objetivos que se destacam na vida política daqueles que seguem líderes ou atores políticos: (1) trata-se de uma forma de obter informação política rápida e sem filtros; (2) preenche o anseio dos usuários que desejam ser parte do processo político e não só receptores de informação; e (3) é uma ferramenta de negócio para quem trabalha com política ou faz a cobertura de notícias políticas.

Por essas razões, compreendendo a importância política dessa mídia social, o objetivo do artigo é, a partir de relatos publicados a esse respeito, verificar os usos que os atores políticos brasileiros têm feito dela. Para isso foi feita uma revisão de literatura entre os anos de 2009 e 2012 buscando trabalhos que relacionassem o Twitter à política, na tentativa de desvendar o que o Twitter pode fazer pela comunicação política.

O recorte específico desses anos deve-se a dois fatores. Primeiro porque é somente depois do fenômeno das eleições presidenciais norte-americanas de 2008 que se tem dimensão das potencialidades dos media sociais para a política. Segundo porque é somente a partir de 2009 que a regulamentação brasileira permite a utilização dos sites de redes sociais em campanhas, o que populariza seu uso político de forma geral. A soma desses fatores faz com que se crie uma vasta agenda de pesquisa para a comunicação política a partir 
deste período e se observe uma produção acadêmica crescente e, em tese, diversificada.

Desta maneira, os trabalhos brasileiros que tratam do tema política e Twitter foram mapeados para que pudéssemos entender como se dão os mecanismos de interação entre políticos e opinião pública no caso brasileiro. Assim, a própria bibliografia do presente artigo nos embasou para a criação de categorias sobre os usos e finalidades com as quais o Twitter tem sido utilizado por atores políticos brasileiros. Tais categorias resultaram em um inventário dos mecanismos de interação que compreende os anos de 2009 a 2012.

\section{Comunicação e Política e a esfera de visibilidade pública}

Frequentemente, a interface presente na ideia de comunicação política é entendida como se o universo político entrasse com o propósito, os agentes, suas habilidades, sua arte, seus valores e seus conteúdos, enquanto a comunicação funcionaria apenas como um conjunto de dispositivos de exibição e difusão dos conteúdos que a política, com suas artimanhas e agilidades, moldaria e formataria segundo seus propósitos e conveniências (GOMES, 2004). Todavia, por se apoiar apenas em uma compreensão leviana dos insumos que o universo da comunicação de massa investe na interface com a política, esta concepção não condiz com a real dinâmica entre os campos.

Segundo Miguel e Biroli (2010), há quatro dimensões principais nas quais a presença dos media fez com que se alterassem as práticas políticas. A primeira é a de que "a mídia tornou-se o principal instrumento de contato entre a elite política e os cidadãos comuns" (MIGUEL e BIROLLI, 2010, p. 9). E, por conta disso, houve uma transformação no discurso político (segunda dimensão), transformação essa que levou o discurso político a se adaptar à linguagem, à 
dinâmica e às práticas dos meios de comunicação (ADATTO, 1990; BUCY; GRABE, 2007; HALLIN, 1994; GOMES, 2009).

A terceira dimensão aponta que outra maneira de a mídia alterar as práticas políticas é através da sua capacidade de formular as questões públicas ou ainda de produzir a agenda pública, prática que é em grande parte condicionada pela visibilidade de cada questão nos meios de comunicação (MIGUEL; BIROLI, 2010). Constatada a capacidade dos meios de comunicação de formularem questões públicas a partir da produção da agenda pública, emerge a quarta dimensão apontada pelos autores, que versa justamente sobre a preocupação central que os candidatos a posições de destaque político devem ter com a gestão da visibilidade, haja vista que ela é condição necessária para a ascensão política (MIGUEL; BIROLI, 2010). Há, então, um reconhecimento da sua importância de modo que esta passa, portanto, a ser fator central e determinante aos estudos sobre o enlace entre os campos da comunicação e da política.

Cria-se, assim, uma dependência entre os campos (GOMES, 2004; MIGUEL; BIROLI, 2010; WEBER, 2006). Atores políticos e instituições lutam para alcançar a visibilidade e imagem convenientes, ao mesmo tempo em o próprio jornalismo precisa dos atores políticos e instituições como fontes. Sabendo desta dinâmica, profissionais do campo político vão utilizar todos os recursos disponíveis para que os atores políticos consigam um espaço nos media.

Acontece que, aos estudiosos de diversos campos das ciências sociais - cientistas políticos, sociólogos, antropólogos etc. - está clara a existência e importância de duas esferas da sociedade: a esfera política e a civil. Mas a estes pesquisadores não é clara a existência de uma esfera intermediária, a chamada esfera de visibilidade pública (EVP), arena que abrange as questões cruciais para o entendimento da dinâmica e da relação entre os campos da comunicação e da 
política, como a formulação de problemas sociais ${ }^{2}$, agendamento ${ }^{3}$, enquadramento ${ }^{4}$, ondas políticas ${ }^{5}$ etc. Desta maneira, estudiosos das ciências sociais, políticas e afins devem considerar não apenas a existência de uma esfera que medeia a relação entre a sociedade e o campo político, mas também o fato de que esta EVP controla as matérias-primas essenciais a todos os atores políticos: visibilidade e imagem.

Para Gomes, a esfera de visibilidade pública é:

\begin{abstract}
a esfera política no seu modo de existir para o cidadão e no modo como pode ser por ele experimentada (...) é nela e por ela que a esfera civil forma a sua opinião e organiza a sua disposição sobre os sujeitos políticos, sobre o estado da coisa pública, sobre agendas e prioridades do congresso, do governo e da sociedade. Do ponto de vista da esfera política, a esfera de visibilidade pública é a forma com que um agente político ou uma matéria de pauta política, por exemplo, podem assegurar o reconhecimento público da sua existência. Para um agente profissional da política, existir para o público de massa é principalmente existir nessa esfera e a imagem que se fizer dele a partir da cena política será tomada pelo público como a constituição de sua natureza e do seu caráter (GOMES, 2004, p.115).
\end{abstract}

Neste contexto, atores políticos estão sempre em campanha e buscando promover-se; a preocupação, em política, gira em torno de fazer propaganda, fazer-se visível, aproveitar as oportunidades de aparecer através dos media.

\title{
2. Desintermediação da informação, Twitter e comunicação política
}

\footnotetext{
${ }^{2}$ Para maior aprofundamento acerca da formulação dos problemas sociais, ver HILGARTNER e BOSK (1998).

${ }^{3}$ Para maior aprofundamento sobre as teorias do agendamento, ver McCOMBS \& SHAW (1972).

${ }^{4}$ Para maior aprofundamento sobre enquadramento, ver ENTMAN (1993).

${ }^{5}$ Para maior aprofundamento sobre o conceito de ondas políticas, ver WOLFSFELD (2001).
} 
Há poucas dúvidas quanto à internet ter afetado de diversas formas o campo da comunicação política, seja do ponto de vista do rearranjo dos atores políticos, seja pelo viés das campanhas eleitorais ou até mesmo pela criação de novas formas de interação entre políticos e cidadãos. No entanto, o terreno permanece espinhoso quando se trata da dimensão dessas mudanças. A análise do fenômeno, das práticas, das apropriações e das iniciativas vem tomando boa parte da literatura de comunicação política e internet.

Entretanto, o que nos interessa aqui é investigar potenciais e limitações da internet para a comunicação de agentes políticos, mais precisamente via Twitter. Contudo, antes de entrar nessa questão, é preciso estabelecer o ambiente da comunicação política diante das possibilidades dos sites de redes sociais e o que a literatura do campo vem estudando a respeito de como agentes políticos estão usando a internet. Como apontam Coleman e Blumler (2009), mais do que tentar avaliar esse novo cenário como deslocado de práticas comunicacionais anteriores, é preciso interpretar a interface entre a comunicação política e as redes digitais como um processo de reconfiguração e rearrumação de posições no jogo político.

Essa mudança é tida por autores que estudam internet (LEMOS e LÉVY, 2010; RAD e VEDEL, 2006; COLEMAN e BLUMLER, 2009) como outro fator decisivo nas novas dinâmicas de comunicação política contemporânea. O fluxo da comunicação se expande e, com ele, a audiência se fragmenta em cidadãos com diversas possibilidades de apropriação do meio. Esse ambiente político deixa de ser controlado pelos dois atores que historicamente o dominavam (mídia e políticos) e passa a ter a presença frequente e atuante dos cidadãos, deixando subir à margem uma dimensão vertical de comunicação em duas vias (BRANTS e VOLTMER, 2011). Claro que isso não quer dizer que indivíduos dominem o novo meio e se tornem automaticamente mais interessados em política, porém é preciso compreender que todos passam a ter - pelo menos em potência - as mesmas 
oportunidades de produção e consumo de informação. Essa arena de comunicação reconfigurada permite $\mathrm{o}$ desenvolvimento, por exemplo, de práticas de conversação civil mais elaboradas (MARQUES, 2006), que podem ser utilizadas por políticos como espaços importantes de diálogo com seu eleitorado.

Como apontam Susha e Gronlund (2012), trabalhos que tratem da interface política e sites de redes sociais ainda são escassos no campo da comunicação política. Dentre os que se destacam por essa linha estão os estudos que envolvem discussão política em períodos eleitorais, mais notadamente pesquisas empíricas (WILLIAMS e GULATI, 2008; PARVIAINEN et al., 2012), ou aqueles que se debruçam sobre análises pontuais de eventos políticos de relevância (REIS e BARROS, 2011; TUFEKCI e WILSON, 2012; LIM, 2012).

A verdade é que de modo geral as características mais interativas oferecidas pela Web 2.0 aparecem como rica fonte de recursos que podem ser postos a serviço da comunicação política (PARLAMEE; BICHARD, 2012; AGGIO, 2010). A ação de compartilhamento no Facebook ou a replicação de mensagens no Twitter, por exemplo, revelam um alargamento nas relações de contato, partilha ou interação entre os usuários, independente deles pertencerem a uma mesma rede social. No caso da informação política ela também pode ser transmitida e trocada através de interações sociais, o que parece ter papel importante para o aprendizado político, formação da atitude e comportamento (ZHANG et al., 2010)

Esse diagnóstico parte do pressuposto de que os cidadãos passam a ter acesso a mais informação de forma geral, o que inclui, obviamente, informação de caráter político. Na visão de Bennet e Iyengar (2008), este é o principal impacto da internet sob o campo da comunicação política: para os cidadãos, que, entre outros aspectos, têm oportunidade de preencher melhor seu repertório informativo; para grupos de interesse, que, dentre outras possibilidades, ampliam 
seus raios de ação a partir da oportunidade de interação em rede; e para os agentes políticos, capazes de organizar novas estratégias de campanha, comunicação direta com seu eleitorado, mobilizar interessados e sondar opinião sobre questões pontuais.

Superando o debate sobre se os sites de redes sociais são bons ou ruins para a política e para a democracia, os estudos empíricos desta área estão começando a formar uma imagem de como esta forma de comunicação pode afetar a participação política e o modo como os agentes políticos interagem com seus eleitores (ANCU; COZMA, 2009; GUSTAFSSON, 2012).

O Twitter, objeto de estudo deste trabalho, foi criado pela empresa Obvious, em 2006, e é caracterizado como microblog que permite aos usuários enviar ou receber atualizações que contenham, no máximo, 140 caracteres. De acordo com o próprio site, ao completar 7 anos de lançamento no início de 2013, o número total de usuários ativos era de 200 milhões, gerando mais de 400 milhões de tweets por dia e sendo aproximadamente 33 milhões de brasileiros. Segundo uma pesquisa realizada pela agência Bullet ${ }^{6}$, esse público é composto, em sua maioria, por homens (61\%) na faixa de 21 a 30 anos (65\%), solteiros $(82 \%)$, cursando ensino superior $(37 \%)$ ou já o tendo completado (31\%). A pesquisa ainda afirma que $60 \%$ do total de usuários são considerados formadores de opinião e possuem um blog pessoal.

Em termos de política, a literatura atual sobre o Twitter vem suscitando, principalmente, o debate sobre como políticos usam a ferramenta em época de campanha. Esse aspecto poderá ser comprovado na seção seguinte, quando se analisará a bibliografia

\footnotetext{
${ }^{6} \mathrm{~A}$ pesquisa a seguir foi realizada pela agência Bullet com 3.268 brasileiros, usuários da rede de microblogging Twitter, com o objetivo de traçar o cenário do Brasil no Twitter e mapear o perfil dos usuários da ferramenta. Disponível em: $<\mathrm{http} / / / \mathrm{www} . \mathrm{mestreseo.com} \cdot \mathrm{br} / \mathrm{twitter}-\mathrm{seo} / \mathrm{estatisticas}-\mathrm{twitter}$-brasil>. Acesso $30 \mathrm{Jul}$. 2011.
} 
nacional a respeito; entretanto, pode-se afirmar que autores internacionais não se restringem apenas a esse caminho. Tumasjan et al. (2010), por exemplo, analisaram o cenário político alemão e os tweets sobre o pleito, concluindo ser possível prever o resultado das eleições a partir de tal análise. Esse estudo levou Jungherr et al. (2012) a rebaterem os resultados, mostrando que é arbitrário qualquer tipo de previsão nesse sentido, pois a publicação de tweets não necessariamente reflete votos e sim intenção de voto.

Já Saebo (2011) e Sala e Jones (2012) se preocupam com outros aspectos do uso do Twitter por parte dos políticos, focando suas análises em períodos não eleitorais. O primeiro faz um apanhado geral de usos a partir da análise de 473 tweets postados por 102 parlamentares, resultando num conjunto de cinco propósitos comunicativos das mensagens: oferecimento de informação a outro usuário, informação sobre atividades representativas em curso, expressão de visão política sobre determinado assunto, assuntos privados e participação em discussão com outro parlamentar. No estudo de Sala e Jones (2012) foi possível identificar que políticos com posicionamentos moderados usam mais o Twitter que aqueles conservadores, indicando que os mais jovens prevalecem no uso da ferramenta.

Esses breves exemplos mostram a diversidade de possibilidades e apropriações que podem existir para a exploração de políticos e partidos, além de fornecer subsídios para estudos mais diversos. Embora a prevalência no Brasil seja de análises em períodos de campanhas, a análise do presente artigo mostra também a variedade de trabalhos que buscam compreender como o Twitter é usado pelos parlamentares nacionais. 
3. Twitter e Comunicação Política: dos usos às possibilidades

Para descrever os mecanismos de interação entre políticos e opinião pública no caso brasileiro, foi realizado um estado da arte buscando mapear trabalhos que tratam de alguma forma do tema política e Twitter (ver tabela I). Esse levantamento possibilitou um inventário dos mecanismos de interação observados especialmente nos últimos anos com o crescimento da web 2.0.

Como se pode observar, entre os anos de 2009 e 2012 foi possível encontrar exatamente 50 trabalhos brasileiros, entre artigos publicados em periódicos, anais, trabalhos de conclusão de curso e livros que tratam do uso da ferramenta por atores políticos. Deste total, 36 publicações são especificamente sobre o uso do microblog em situações de campanha e 33 são relatos de experiência do seu uso geral. 
Quadro 1 - Quadro geral das categorias de análise

\begin{tabular}{|c|c|c|}
\hline Cathoris & 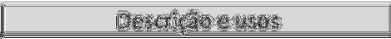 & Treteredras \\
\hline 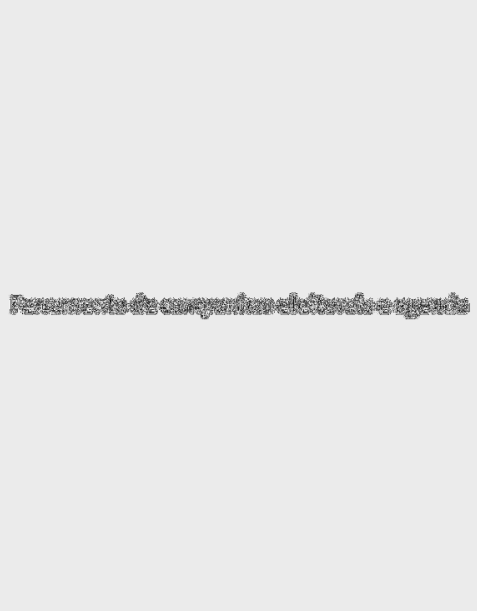 & 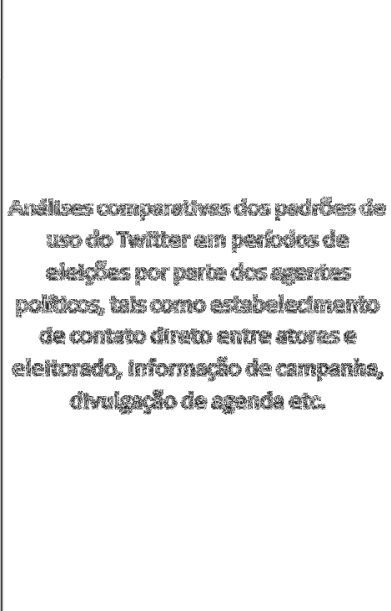 & 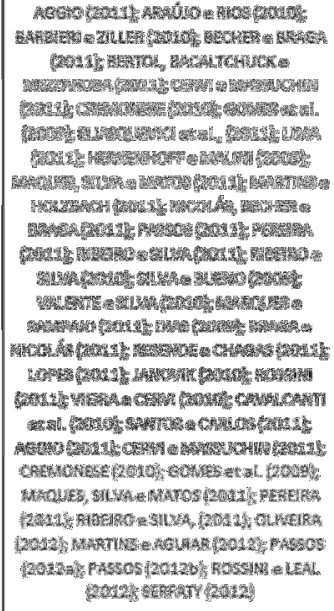 \\
\hline Mobilikagato & 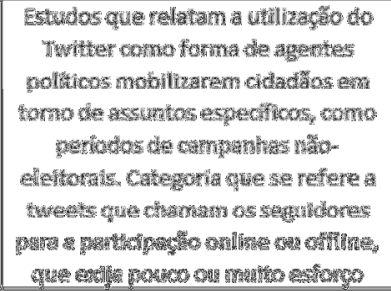 & 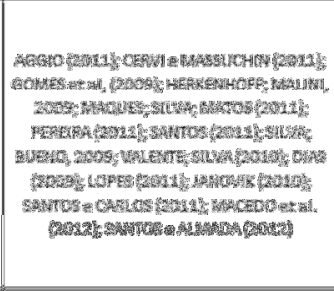 \\
\hline 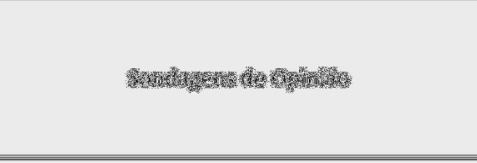 & 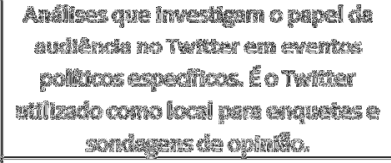 & 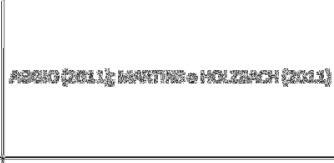 \\
\hline 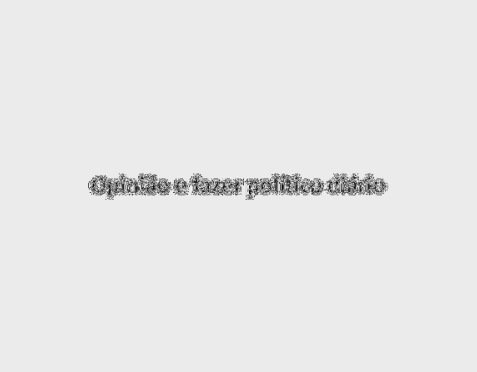 & 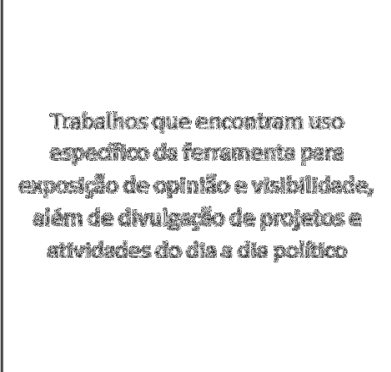 & 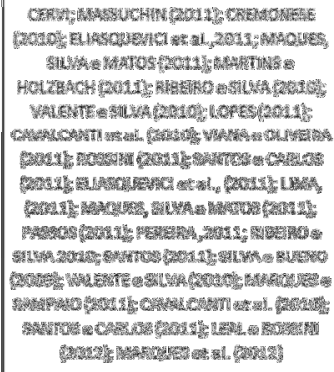 \\
\hline autros & $\begin{array}{l}\text { Trabalhos qua ndo se ançuadram em } \\
\text { nenhuma das categorias anteriores }\end{array}$ & 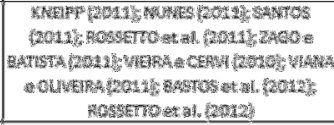 \\
\hline
\end{tabular}

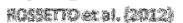

Esse levantamento possibilitou entender com quais finalidades o Twitter tem sido usado por atores políticos brasileiros, o que prontamente confirmou o que se supunha sobre seu uso relacionado às eleições: a grande maioria dos trabalhos aborda a sua utilização como ferramenta de campanhas eleitorais e agenda. Em seguida, os usos mais relatados, em ordem decrescente, foram: opinião e fazer político diário, mobilização; outros e sondagens de opinião. 
Essas categorias foram criadas com base na observação dos usos relatados pela própria bibliografia específica e para melhor sistematização e organização do trabalho. A primeira delas, que é o uso do Twitter como ferramenta para campanhas eleitorais e agenda, compreende as interfaces que esse canal permite para exposição de informações e conteúdos em formatos variados, a interação com potenciais eleitores e simpatizantes, e a organização de grupos para a execução de tarefas e ações de mobilização (AGGIO, 2011) com o objetivo de conquistar votos.

Um bom exemplo de relato desse tipo de uso é oferecido por Becher e Braga (2011) a respeito dos mecanismos de participação e deliberação on-line nas últimas eleições brasileiras. O trabalho apresenta resultados sobre o uso da internet pelos candidatos aos governos dos estados e ao senado nas eleições de 2010 a partir de uma metodologia adaptada para detectar padrões de uso da internet e mapear diferentes modalidades de interação entre candidatos e eleitores. Como resultado, verificou-se que as regiões sul e sudeste apresentam percentuais superiores de candidatos usuários de website, de mídias sociais e de Twitter. Além disso, variáveis estritamente políticas, e não apenas referentes ao padrão de distribuição dos recursos socioeconômicos vigentes em cada região do país, influenciaram de maneira mais significativa o padrão de uso da web pelos candidatos.

Isso significa que o candidato mediano, usuário das novas mídias nas eleições majoritárias de outubro de 2010, apresentou as seguintes características: concentrado nas regiões centro-oeste, sul e sudeste do Brasil, pertencente aos grandes partidos com maior capacidade de mobilização de recursos políticos, com maior experiência política e maior escolaridade. Por fim, duas características básicas sobre o uso da web no último pleito foram: (1) atenuação da exclusão digital entre os candidatos de diferentes regiões do país e tendências ao uso generalizado e mais igualitário das novas mídias; (2) ampla difusão 
do uso das mídias sociais pelos candidatos, com Twitter, Facebook e postagens de vídeos no Youtube substituindo mecanismos tradicionais de interação como blogs, fóruns e chats.

A segunda categoria trata do uso do Twitter para demonstrações de opinião e fazer político diário; isso significa que a ferramenta é utilizada para exposição de opinião do político e para divulgar projetos e atividades cotidianas que lhe rendam alguma visibilidade favorável. Em seguida vem a categoria que descreve como a ferramenta é utilizada para fins de mobilização, que vai além da mobilização durante o período eleitoral. Trata-se também do movimento do cidadão a respeito de alguma campanha ou situação política que tenha repercussão e gere discussão. É notório que a mobilização em situação de campanha é muito mais frequente na revisão de literatura, mas é possível citar outros usos como relata Santos (2011), por exemplo, a respeito da utilização da hashtag \#dilmafactsbyfolha, que discute a mobilização de usuários do Twitter utilizando essa hashtag depois de uma reportagem publicada pela Folha de São Paulo.

As últimas categorias de usos verificadas foram sondagens de opinião e outros. A primeira versa sobre a possibilidade do ator político elaborar pesquisas de opinião e divulgá-las a partir do seu perfil para sondagem. Essa possibilidade ainda parece muito pouco explorada, e só consta nos relatos de Aggio (2011) e Martins e Holzbach (2011). A segunda engloba publicações que não se encaixavam em nenhum dos usos citados, dentre as quais duas se destacam (VIEIRA; SERVI, 2010; VIANA; OLIVEIRA, 2011).

O conteúdo dos tweets observados no caso brasileiro revela interações sociotécnicas entre atores políticos e entre estes e os cidadãos/eleitores; revela o político como homem comum, bem como seu posicionamento diante da política (SILVA, BUENO e 2009). É, além de uma ferramenta de campanha eleitoral e mobilização, um 
local de exposição de opiniões, sondagens e do fazer político diário para a obtenção de visibilidade pública e, portanto, para a construção da imagem pública conveniente.

Seu grande potencial foi revelado pela repercussão gerada pela campanha virtual de Obama, um indício do tamanho da importância que a internet assumiu nas campanhas eleitorais da atualidade. No entanto, o caso brasileiro guarda diferenças marcantes com o exemplo americano, o que se deve, entre outras razões, por exemplo, às inúmeras diferenças entre o tempo de campanha no Brasil e nos Estados Unidos e da quantidade de pessoas que têm acesso à internet e que veem esse meio como fonte de informação em cada país (LOPES, 2011).

\section{Discussão}

No geral, as ferramentas de comunicação mediadas pelo computador têm grandes potenciais democráticos, que podem ser utilizados por todos os tipos de atores políticos. No caso dos candidatos a cargos eletivos, as possibilidades oferecidas pela Web 2.0 tornam a reprodução de padrões de uso massivos insuficientes.

De acordo com Recuero (2009), há quatro valores que podem ser construídos pelas redes sociais: a visibilidade (que auxilia a manutenção de laços sociais e faz tornar-se conhecido), a reputação (as impressões que um ator social tem do outro), a popularidade (descrita pelo número de comentários e tamanho da audiência) e a autoridade (quantidade de citações, menções ou retweets, além da capacidade de gerar conversações). Todos esses são diretamente relacionados ao campo de interseção entre a comunicação e a política, bem como aos anseios dos atores políticos em disputa por cargos ou por visibilidade. Isso faz com que se compreenda que nesse 
novo ambiente comunicacional criar relacionamentos é fundamental.

No entanto, a inserção dos sites de redes sociais na comunicação política demanda a compreensão de um conjunto de princípios e regras de comportamento, oriundos da sociabilidade construída pelos seus usuários, que devem ser respeitadas para que se tenha sucesso com seus esforços de comunicação. Essa interatividade via Twitter torna-se, então, capaz de transformar essa rede social em um espaço político-midiático-público para a troca de opiniões entre pessoas que fora do ambiente on-line não teriam a oportunidade de se encontrar (VALENTE; SILVA, 2010).

Há um interesse cada vez maior dos estudiosos sobre os impactos da internet nos processos de representação política, na publicização das ações políticas e dos próprios políticos através dela e nos sistemas políticos contemporâneos de uma maneira geral. De maneira específica, neste estudo, inventariando a produção brasileira a respeito do uso político do Twitter chega-se inicialmente a duas conclusões: seu uso é feito predominantemente por políticos profissionais e/ou candidatos a algum cargo eletivo e os padrões de uso ainda são limitados se consideradas as possibilidades da ferramenta 2.0.

O Twitter foi e é uma ferramenta importante, principalmente pela relação que consegue desenvolver com as outras ferramentas disponíveis na rede, como os jornais e blogs jornalísticos (DIAS, 2009). Esse fato é destacado também pela pesquisa norte-americana que se apresenta, com citado anteriormente, em um estado bem mais avançado do que a brasileira, principalmente por oferecer uma fonte de investigação mais rica, dados os padrões de uso, acesso e informação disponível quando se trata da relação entre redes sociais e política. 
No primeiro livro de que se tem conhecimento dedicado à investigação de como o Twitter influencia a relação entre líderes políticos e o público (PARMELEE; BICHARD, 2012), há relatos detalhados e um grande volume de dados que busca explicar como o Twitter está influenciando campanhas, a governança e a relação entre líderes políticos e o público. O uso desta ferramenta pelos atores políticos levanta muitas questões para aqueles que estudam a comunicação política, como, por exemplo, em que grau os tweets políticos influenciam a visão política de um seguidor e o seu comportamento, ou ainda, até que ponto determinado ator político consegue produzir uma imagem pública que lhe seja conveniente perante o eleitorado para o qual ele, através do Twitter, consegue fazer-se visível.

É claro que as realidades políticas de Brasil e Estados Unidos são bastante distintas, chegando inclusive a gerar resultados diferentes quando observamos as utilidades que os media sociais têm para os políticos. É o caso do já citado estudo de Sala e Jones (2012), que identificou que políticos com posicionamentos moderados usam mais o Twitter que aqueles conservadores, indicando que os mais jovens prevalecem no uso da ferramenta; e Ausserhofer e Maireder (2013), analisando a "twitteresfera" política da Áustria, demonstram que os políticos de esquerda são maioria na ferramenta. No caso brasileiro observa-se exatamente o contrário. Em sua pesquisa, Becher e Braga (2011) identificaram que durante as últimas eleições o candidato mediano usuário das ferramentas da web 2.0 era aquele mais velho, mais conservador, pertencente aos grandes partidos, com maior capacidade de mobilização de recursos políticos e maior experiência política.

Essa constatação reflete as profundas diferenças existentes entre o funcionamento do jogo político e da realidade política de cada país, não obstante não diminui a importância do entendimento da variedade dos padrões de uso verificados em realidades distintas. 
Parmelee e Bichard (2012) revelam utilidades que vão além daquelas reportadas nos estudos brasileiros e podem servir tanto de inspiração para prática como de agenda para pesquisa.

Apesar dos usos mais comuns da ferramenta serem os de compartilhar informações, oferecer transparência e funcionar como uma espécie de boca a boca digital, amplificando o discurso, fica claro que o Twitter não é usado somente para campanhas políticas. Agências federais e estaduais empregam o microblog pelas mesmas razões que os políticos, por ser uma forma rápida e fácil de transmitir informação e de interagir com as partes interessadas. Isso é atestado pelo uso crescente que governos locais fazem da ferramenta para "educar a população e tornar os serviços mais eficientes" (PARMELEE; BICHARD, 2012, p. 11).

Sobre o conteúdo dos tweets políticos, as descobertas sugerem que líderes políticos usam mensagens primeiramente para disseminar informação sobre suas políticas e sua personalidade. Interagir com os seguidores ainda é uma prioridade secundária. Assim, também é importante observar o grau em que os líderes políticos usam o Twitter com esse último fim, ao invés de simplesmente utilizarem a ferramenta com características de broadcasting. Aí reside o grande consenso entre as duas pesquisas aqui exemplificadas: a forma como o Twitter é usado e como deveria ser usado. Ambas identificam o caráter de mão única que tem sido empregado pelos atores políticos, deixando de lado as reais potencialidades participativas da ferramenta.

No caso brasileiro, as investigações empíricas existentes sobre o uso da web demonstram que, embora com uma crescente presença de candidatos com websites, especialmente nas eleições majoritárias, ainda são criados poucos espaços de participação e interação com os eleitores, estando a maior parte dos websites de campanha até aqui num estágio pré-Web 2.0 (BRAGA et al., 2009; BRANDÃO JÚNIOR, 
2008). No caso dos Estados Unidos percebe-se também uma exploração aquém do possível e desejado, mas já se observa que aqueles políticos que tiveram sucesso no uso do Twitter foram os que fizeram um esforço para ir além da comunicação de mão única com seus seguidores. No caso do Brasil, até agora pode-se perceber que a utilização do Twitter é como se fosse uma prestação de serviço obrigatória dos candidatos numa relação direta com o eleitor. Essa conclusão pode ser generalizada para a importância da presença dos atores políticos nesta rede social nos períodos que vão além dos eleitorais, sobretudo considerando o estado de campanha política permanente em que vivemos. De toda forma, não há percursos substitutivos ou de descontinuidade. A complementaridade continua sendo o fio condutor da comunicação política na internet.

A realidade é que, além de buscarem a autopromoção e a atenção dos cidadãos, os políticos estão sempre procurando formas de ter suas mensagens transmitidas sem filtros que possam potencialmente alterá-las. O Twitter, bem como outras redes sociais, pode preencher essa necessidade, modificando a forma de se fazer política, mas sem excluir as possibilidades de se chegar à grande esfera de visibilidade pública.

A agenda de pesquisa para esta área revela-se assim tão rica como a própria Web 2.0. Primeiro, acredita-se que seja necessário ampliar a compreensão a respeito de quem são os atores políticos que fazem uso dessas redes e como o fazem. Isso inclui a verificação da presença de instituições e órgãos governamentais, assim como de líderes políticos não somente detentores de cargos nos governos, como também de outras forças emergentes como blogueiros e cidadãos. Observar o fazer político diário dos candidatos eleitos e dos líderes políticos entendidos nesse sentido mais amplo, é mais uma possibilidade capaz de enriquecer os relatos de até então, oferecendo resultados que perpassam a compreensão do uso da ferramenta somente em momentos eleitorais. 


\section{Considerações finais}

A pesquisa sobre o impacto do Twitter também cobre o conteúdo de milhões de mensagens encontradas no microblog. Tal análise revela por que o Twitter é uma ferramenta valiosa para medir a opinião pública. Os sentimentos expressos nas mensagens a respeito de questões políticas podem ser uma medida tão precisa da opinião pública quanto aquela encontrada nas tradicionais surveys por telefone. Os resultados das pesquisas sugerem que os usuários do Twitter não devem ser considerados uma parcela que não reflete a população geral, mas ao invés disso, um grupo cujas opiniões são (pelo menos coletivamente) representativas (PARMELEE; BICHARD, 2012).

Como os media sociais continuam a crescer em tamanho e influência, muito se questiona sobre o efeito que eles terão na sociedade e na democracia. Enquanto algumas pesquisas sugerem que a dependência da sociedade dos media sociais pode influenciar positivamente o engajamento cívico, alguns efeitos negativos também são aparentes. Um receio é que os usuários das redes sociais on-line dispensem mais tempo interagindo remotamente do que face a face, uma tendência que pode inibir as habilidades sociais nos relacionamentos presenciais. Além disso, há a preocupação sobre o que $\mathrm{o}$ anonimato pode permitir, sem falar na possibilidade dos indivíduos se isolarem politicamente, fechando-se à pluralidade que é essencial à democracia.

Contudo, todas essas são preocupações que não são fruto do surgimento e crescimento dos media sociais, mas sim da própria internet relacionada à política. $\mathrm{O}$ que se estabelece com o advento da Web 2.0 trata-se de uma relação nova e poderosa. As razões para seguir um líder político são diversas, vão desde uma espécie de utilidade social - que significa que a informação política obtida pode 
ajudar em termos de interação social quando em discussões políticas com conhecidos, seja pessoalmente ou no Twitter - até o entretenimento (PARLAMEE; BICHARD, 2012). Essa variedade de motivações e o conteúdo do que se publica faz com que o Twitter seja uma via bastante útil para os atores políticos, já que os permite informar e influenciar uma audiência que se dissemina muito além dos seus grupos de seguidores.

Em última instância, a capacidade de um tweet influenciar a sua audiência é a receita essencial que se deseja descobrir. $O$ que se sabe até então é que o uso político do Twitter aumentou o ativismo, tornou os usuários mais questionadores, curiosos e informados, forçando todos os usuários a serem mais concisos e claros, mudando - modo como os negócios políticos interagem com os cidadãos/eleitores e influenciando como as notícias passam por outras plataformas midiáticas. 


\section{Referências}

ADATTO, K. The Incredible Shrinking Sound Bite. The New Republic, 28 de maio d e 1990, p. $20 \square 23$.

AGGIO, C. As campanhas políticas no Twitter: Uma análise do padrão de comunicação política dos três principais candidatos à presidência do Brasil em 2010. In: III Congresso da Associação Brasileira de Pesquisadores em Comunicação e Política, 2009, São Paulo. Anais III Congresso Compolítica, 2011.

Dos websites aos media sociais: Apontamentos sobre os recursos e práticas de publicidade das campanhas eleitorais nos ambientes digitais. In: III Seminário Nacional de Ciência Política, 2010, Porto Alegre. Anais do III Seminário Nacional de Ciência Política, 2010.

Campanhas Online: O percurso de formação das questões, problemas e configurações a partir da literatura produzida entre 1992 e 2009. In: Opinião Pública, Campinas, vol. 16, n 2, Novembro, 2010.

ARAUJO, G. F.; RIOS, R. Estratégias do Marketing Político Digital aplicadas à campanha presidencial de Barack Obama. In: XXXIII Congresso Nacional da Intercom, 2010, Caxias do Sul. Anais do XXXIII Congresso da Intercom 2010.

BARBIERI, M.; ZILLER, J. Follow em mim: a disputa presidencial em 140 caracteres. In: XXXIV Congresso Nacional da Intercom, 2011, Recife. Anais do XXXIV Congresso da Intercom 2011.

BASTOS, M. T. et al. Gatekeeping em tempos de Twitter: A emergência de Trending Topics políticos no Twitter. In: XXI Congresso da Associação Nacional dos Programas de Pós-graduação em Comunicação, 2012, Juiz de Fora. Anais do XXI Congresso Compós, 2012.

BERTOL, S. R. S.; BACALTCHUCK, B.; MEZZAROBA, M. P. A Campanha Eleitoral na Internet: Uma Análise do Twitter dos Candidatos à Presidência Dilma Roussef e José Serra. Revista Democracia Digital e Governo Eletrônico, n 5, 2011, p. 172185.

BENNET, L.; IYENGAR, S. A New Era of Minimal Effects? The Changing Foundations of Political Communication. In: Journal of Communication, vol 58. 2008.

BRAGA, S. O que a internet agrega às eleições? Um balanço inicial do uso da internet pelos candidatos aos governos estaduais e ao senado federal nas eleições brasileiras de outubro de 2010. In: IV Congresso Latino Americano de Opinião Pública da WAPOR, 2011, Belo Horizonte. Anais do IV Congresso Latino Americano de Opinião Pública da WAPOR, 2011.

BRECHER, A.; BRAGA, S. Mecanismos de participação e deliberação on-line nas eleições de outubro de 2010 no Brasil. In: Seminário Nacional Sociologia \& Política, 2011, Curitiba. Anais do Seminário Nacional Sociologia \& Política, 2011.

BERTOL, S. R. S. et al. A Campanha Eleitoral na Internet: Uma Análise do Twitter dos Candidatos à Presidência Dilma Roussef e José Serra. In: XXXIV Congresso 
Nacional da Intercom, 2011, Recife. Anais do XXXIV Congresso da Intercom 2011.

BUCY, Erik P.; GRABE, Maria Elizabeth. Taking television seriously: a sound and image bite analysis of presidential campaign coverage, 1992-2004. Journal of Communication, 57(4), 2007, p. 652-675.

CANAVILHAS, J. A. Comunicação Política na Era da Internet. Disponível em: http://www.bocc.ubi.pt/pag/canavilhas-joao-comunicacao-politica-na-erada-internet.pdf. 2009. Acesso em: 25/6/2012.

CAVALCANTI, A. C. et al. Redes sociais e política: as influências do uso do Twitter na construção da figura política do governador Cid Gomes. In: XXXIII Congresso Nacional da Intercom, 2010, Caxias do Sul. Anais do XXXIII Congresso da Intercom 2010.

CERVI, E. U.; MASSUCHIN, M. G. O uso do Twitter nas eleições de 2010: o microblog nas campanhas dos principais candidatos ao governo do Paraná. Contemporanea, v. 9, n. 2, 2011, p. 319-334.

COLEMAN, Stephen; BLUMLER, Jay G. The Internet and Democratic Citizenship: theory, practice and Policy. Cambridge University Press, Cambridge, UK. 2009.

CREMONESE, D. Redes Sociais e Política no Brasil: a utilização do Twitter nas eleições 2010. In: IV Congresso Latino Americano de Opinião Pública da WAPOR, 2011, Belo Horizonte. Anais do IV Congresso Latino Americano de Opinião Pública da WAPOR, 2011.

A política brasileira passa pelo Twitter: a utilização dos meios eletrônicos nas eleições 2010. In: III Seminário Nacional de Ciência Política, 2010, Porto Alegre. Anais do III Seminário Nacional de Ciência Política, 2010.

DAHLGREN, P. The Internet, Public Spheres, and Political Communication: Dispersion and Deliberation. Political Communication, 22:147-162, 2005.

DIAS, A. Democracy in 140\#. In: IV Congresso de la CiberSociedade, 2009. Disponível <http://www.cibersociedad.net/congres2009/es/coms/democracy-in-140/957/>

ELIASQUEVICI, C. et al. Microblogs como Espaço de Propaganda Política: um Estudo de Caso do Twitter. Revista Anagrama, ano 5, n. 1, 2011.

ENTMAN, Robert M. Framing: Toward Clarification of a Fractured Paradigm. Journal of Communication; 1993.

GOMES, W. et al. "Politics 2.0": A Campanha Online de Barack Obama em 2008. Revista Sociologia e Política, v. 17, n. 34, 2009, p. 29-43.

GOMES, W. Internet e Participação Política. In: GOMES, W.; MAIA, R. C. M. Comunicação e Democracia: problemas \& perspectivas. São Paulo: Paulus, 2008. 
Audioesfera política e visibilidade pública: os atores políticos no Jornal Nacional. PDF, 2009.

Transformações da política na era da comunicação de massa. São Paulo: Paulus, 2004.

Opinião política na internet: uma abordagem ética das questões relativas à censura e liberdade de expressão na comunicação em rede. In: $\mathrm{X}$ Congresso da Associação Nacional dos Programas de Pós-graduação em Comunicação, 2001, Brasília. Anais do X Congresso Compós, 2001.

HALLIN, D. Soundbite news: television coverage of elections, $1968 \square 1988$. In: HALLIN, D. We keep America on top of the world: Television journalism and the public sphere. New York: Routledge, 1994: p. 133 $\square 152$.

HERKENHOFF, G.; MALINI, F. A ciberpolítica nas eleições municipais de 2008: da obstrução à produtividade da comunicação na rede. In: XXXII Congresso Nacional da Intercom, 2009, Curitiba. Anais do XXXII Congresso da Intercom, 2009.

HILGARTNER, S.; BOSK, C. The rise and fall of social problems: A public arenas mod el. American Journal of Sociology, 94(1), 1988, p. $53 \square 78$.

JANOVIK, C. Pré-campanha online de Dilma e Serra: o uso da internet pelos candidatos às eleições presidenciais de 2010. Trabalho de Conclusão de Curso, UFRGS, 2010.

JUNGHERR, A.; JURGENS, P.; SCHOEN, H. Why the Pirate Party Won the German Election of 2009 or The Trouble With Predictions: A Response to Tumasjan, A., Sprenger, T. O., Sander, P. G., \& Welpe, I. M. Predicting Elections With Twitter: What 140 Characters Reveal About Political Sentiment. In: Social Science Computer Review 30(2) 229-234, 2012.

KNEIPP, V. A. P. O processo de Gatekeeping no telejornalismo - um estudo do uso do Twitter no Jornal Nacional. In: Seminário Internacional Análise de Telejornalismo, 2011, Salvador. Anais do Seminário Internacional Análise de Telejornalismo, 2011.

LEAL, P. R. F.; ROSSINI, P. G. C. Relações entre representantes e representados no Twitter: os perfis de presidentes latino-americanos e a construção de uma agenda de pesquisa. In: XXI Congresso da Associação Nacional dos Programas de Pósgraduação em Comunicação, 2012, Juiz de Fora. Anais do XXI Congresso Compós, 2012.

LEMOS, A.; LÉVY, P. O futuro da internet: em direção a uma ciberdemocracia planetária. Ed. Paulus: São Paulo. 2010.

LIMA, E. C. A. O uso das redes sociais na campanha presidencial de Dilma Rousseff. In: XXVIII Congresso Internacional da Alas, 2011, Recife. Anais do XXVIII Congresso Internacional da Alas, 2011.

LIPPMANN, Walter. Public Opinion. La Vergne: BN Publishing, 2010 [1922]. 
LOPES, N. F. A. Política na rede: Papel das redes sociais da internet na campanha eleitoral para a Presidência da República no Brasil em 2010. In: IV Congresso Latino Americano de Opinião Pública da WAPOR, 2011, Belo Horizonte. Anais do IV Congresso Latino Americano de Opinião Pública da WAPOR, 2011.

MACEDO, F. V. A. B. et al. Virtualidades em Movimento e Ciberdemocracia: \#foramicarla em Natal - RN. Revista de Economía Politica de las Tecnologias de La Información y de La Comunicación, v. 14, n. 1, 2012.

MARQUES, F. P. J. A. Debates políticos na internet: a perspectiva da conversação civil. In: Opinião Pública, Campinas, vol. 12, nํ1, Abril/Maio, 2006.

MARQUES, F. P. J. A. et al. Parlamentares, representação política e redes sociais digitais: perfis de uso do Twitter na Câmara dos Deputados. In: XXXVI Encontro Anual da Anpocs, 2012, Águas de Lindóia. Anais do XXXVI Encontro Anual da Associação Nacional de Pós-graduação e Pesquisa em Ciências Sociais, 2012.

MARQUES, F. P. J. A.; SAMPAIO, R. C. Election after election: Rupturas e continuidades nos padrões mediáticos das campanhas políticas online. In: XX Congresso da Associação Nacional dos Programas de Pós-graduação em Comunicação, 2011, Porto Alegre. Anais XX Congresso Compós, 2011.

MARQUES, F. P. J. A.; SILVA, F. W. O.; MATOS, N. R. A. Estratégias de comunicação política online: uma análise do perfil de José Serra no Twitter. In: 35 Encontro Anual da Associação Nacional de Pós-graduação e Pesquisa em Ciências Sociais, 2011, Caxambu. Anais do XXXV Encontro Anual da Associação Nacional de Pós-graduação e Pesquisa em Ciências Sociais.

MARTINS, A. V.; AGUIAR, L. F. Convergência e Transmídia nos debates dos candidatos ao governo da Paraíba: a Rede Paraíba de Comunicação nas Eleições 2010. Estudos em Jornalismo e Mídia, v. 9, n. 1, 2012, p. 109-120.

MARTINS, A. F.; HOLZBACH, A. O eleitor tem a força! Os comentários dos eleitores no Twitter e o papel da audiência nos debates presidenciais. In: XXXIV Congresso Brasileiro de Ciências da Comunicação, 2011, Recife. Anais do XXXIV Congresso da Intercom, 2011.

McCOMBS, E. Maxwell; SHAW, Donald L. The agenda setting function of mass media. The Public Opinion Quarterly, vol. 36, n. 02, 1972, p.176-187, 1972.

MIGUEL, Luís Felipe; BIROLI, Flávia. Comunicação e Política: um campo de estudos e seus desdobramentos no Brasil. In: MIGUEL, Luís Felipe; BIROLI, Flávia (org.). Mídia, representação e democracia. São Paulo: HUCITEC, 2010. p. 7-24.

NICOLÁS, M. A.; BECHER, A.; BRAGA, S. Elites políticas e NTICs: uma análise do uso da internet pelos candidatos aos governos estaduais e ao senado nas eleições brasileiras de outubro de 2010. In: 35 Encontro Anual da Associação Nacional de Pós-graduação e Pesquisa em Ciências Sociais, 2011, Caxambu._Anais do 35 Encontro Anual da Associação Nacional de Pós-graduação e Pesquisa em Ciências Sociais, 2011. 
OLIVEIRA, J. A. de. Redes sociais e participação política na esfera pública. Revista de Economía Politica de las Tecnologias de La Información y de La Comunicación, v. 14, n. 1, 2012.

SAEBO, O. Undestanding Twitter Use among Parliament Representatives: a Genre Analysis. In: Third IFIP WG 8.5 International Conference, Eletronic Participation. TAMBOURIS, E.; MACINTOSH, A.; BRUIJIN, H.; $1^{\circ}$ de setembro, 2011.

SALA, J. F. A.; JONES, M. P. The Use of Eletronic Technology and Legislative Representation in Mexican and U.S. States: Nuevo León and Texas. In: Puentes Consortium Project, abril de 2012.

SANTOS, N.; ALMADA, M. P. Twitter e as marchas anticorrupção: Uma análise do posicionamento discursivo da manifestação em relação ao sistema político. Revista Eletrônica do Programa de Pós-graduação da Faculdade Cásper Líbero, v. 4, n. 4, 2012, p. 1-12.

SANTOS, N. As transformações da mediação e o poder do cidadão: o caso da hashtag "\#dilmafactsbyfolha". In: III Congresso da Associação Brasileira de Pesquisadores em Comunicação e Política, 2009, São Paulo. Anais III Congresso Compolítica, 2011.

SERFATY, V. E-Povo: uma perspectiva comparada sobre o uso de redes sociais nas campanhas eleitorais dos Estados Unidos e França. Revista Comunicação Midiática, v.7, n.3, 2012, p.195-214.

NUNES, M. R. F.; BIN, M. A. Xenofobia e Participação Política nas Redes Sociais. In: Congresso da Confederação Íbero-Americana das Associações Científicas e Acadêmicas de Comunicação, 2011, São Paulo. Anais do Congresso da Confibercom, 2011.

O’REILLY, Tim. What is Web 2.0: Design Patterns and Business Models for the Next Generation of Software. Communications \& Strategies, n. 1, p. 17, First Quarter 2007.

PARMELEE, John H.; BICHARD, Shannon L. Politics and the Twitter Revolution: How Tweets Influence the Relationship between Political Leaders and the Public. Maryland: Lexington Books, 2012.

PASSOS, M. R. Narrativa biográfica no Twitter: A auto-entrevista midiática em @silva_marina. Rumores, v. 11, n. 1, 2012a, 123-144.

. O Twitter como trincheira de luta política e ideológica: um estudo sobre o microblog de Hugo Chávez. In: XXXVI Encontro Anual da Anpocs, 2012b, Águas de Lindóia. Anais do XXXVI Encontro Anual da Associação Nacional de Pósgraduação e Pesquisa em Ciências Sociais, 2012.

PEREIRA, N. B. Sob o Piado do Twitter: o Novo Tom das Campanhas Eleitorais com a Difusão da Internet no Brasil - Versão Reformulada. In: Seminário Nacional Sociologia \& Política, 2011, Curitiba. Anais do Seminário Nacional Sociologia \& Política, 2011. 
RECUERO, Raquel da Cunha. Redes Sociais na Internet. Porto Alegre: Sulina, 2009. 191 p. (Coleção Cibercultura).

RESENDE, J. F.; CHAGAS, J. S. C. Eleições no Brasil em 2010: comparando indicadores político-eleitorais em surveys e na internet. In: IV Congresso Latino Americano de Opinião Pública da WAPOR, 2011, Belo Horizonte. Anais do IV Congresso Latino Americano de Opinião Pública da WAPOR, 2011.

RIBEIRO, Carina F. B.; SILVA, Erica Anita B. Onda verde: a campanha online e offline de Marina Silva em 2010. In: IV Congresso Latino Americano de Opinião Pública da WAPOR, 2011, Belo Horizonte. Anais do IV Congresso Latino Americano de Opinião Pública da WAPOR, 2011.

RIBEIRO, C. F. B.; SILVA; E. A. B. Internet na eleição 2010: uso das redes sociais por Dilma Rousseff na campanha eleitoral. In: III Seminário Nacional de Ciência Política, 2010, Porto Alegre. Anais do III Seminário Nacional de Ciência Política, 2010.

ROSSETTO, G. P. N. et al. Twitter e comunicação política: limites e possibilidades. In: VIII Encontro da ABCP, 2012, Gramado. Anais do VIII Encontro da ABCP, 2012.

Telejornalismo, Agenda-Setting e Twitter: possibilidade metodológica para o teste de efeitos comportamentais. In: Seminário Internacional Análise de Telejornalismo, 2011, Salvador. Anais do Seminário Internacional Análise de Telejornalismo, 2011.

ROSSINI, P. G. C. Participação Política na Era Digital: um estudo de caso das \#Eleições2010. In: IX Encontro Regional de Comunicação, 2011, Juiz de Fora. Anais do IX Encontro Regional de Comunicação, 2011.

ROSSINI, P. G. C.; LEAL, P. R. F. Campanhas On-line e a Decisão do Voto:

O Twitter como Atalho Informacional nas Eleições 2010. In: XXXV Congresso Brasileiro de Ciências da Comunicação, 2012, Fortaleza. Anais do XXXV Congresso da Intercom, 2012.

SANTOS, N.; CARLOS, J. (Orgs.). Mídias sociais e eleições 2010. Ebook, 2011. Disponível em: <http://www.papercliq.com.br/ebook-midias-sociais-e-eleicoes2010/>.

SANTOS, C. J. M.; SILVA, D. V.; XAVIER, J. R. E. Follow me no Twitter: vote-me no Twitter. O uso da ferramenta nas eleições para o governo do Estado de Pernambuco. Trabalho de Conclusão de Curso, 2010.

SILVA, E. A. B.; BUENO, E. L. Internet e política: os usos do Twitter pelos vereadores de Belo Horizonte. In: III Congresso da Associação Brasileira de Pesquisadores em Comunicação e Política, 2009, São Paulo. Anais III Congresso Compolítica, 2009.

TUMASJAN, A.; SPRENGER, T. O.; SANDNER, P. G.; WELPE, I. M. Predicting Elections with Twitter: What 140 Characters Reveal about Political Sentiment. In: Association for the Advancement of Artificial Intelligence, 2010. 
WEBER, Maria Helena. Visibilidade e credibilidade: tensões da comunicação política. In: CASTRO, Maria Ceres; MAIA, Rousiley (Orgs.). Mídia, esfera pública e identidades coletivas. Belo Horizonte: Editora da UFMG, 2006. p. 117-136.

WOLFSFELD, G. Political waves and democratic discourse: Terrorism waves during the Oslo peace process. In: BENNETT, W. L.; ENTMAN, R. M. (Orgs.). Mediated politics: communication and the future of democracy. Cambridge: Cambridge University Press, 2001, p. 226 $\square 251$.

VALENTE, M. R. M.; SILVA, M. L. H. A utilização do Twitter na campanha política e sua aplicação no Tocantins: estudo de caso do perfil do candidato a Governador eleito Siqueira Campos. In: Congresso Panamericano de Comunicação, 2010, Brasília. Anais do Congresso Panamericano de Comunicação, 2010.

VIANA, David Henrique Moura; OLIVEIRA, Bernardina Maria Juvenal Freire de. Twitter: repositório memorialístico do discurso político parlamentar. In: IV Seminário em Ciência da Informação, 2011, Londrina. Anais do IV Seminário em Ciência da Informação, 2011.

VIEIRA, J. F.; CERVI, E. U. O Twitter como pauta no jornalismo político do Paraná. In: XXXIII Congresso Nacional da Intercom, 2010, Caxias do Sul. Anais do XXXIII Congresso da Intercom 2010.

WARD, S.; VEDEL, T. Introduction: The Potential of the Internet Revisited. Parliamentary Affairs, vol. 59 n. 2, 2006.

ZAGO, Gabriela da Silva; BATISTA, Jandré Corrêa. Ativismo e agendamento nos trending topics do Twitter: o caso Wikileaks. Contemporânea, v.9, n.1, 2011, p. 101-114.

COMPOLITICA ASSOCIACÄO BRASILEIRA DE PESQUISADORES EM COMUNICACÃO E POLITICA

Presidente: Alessandra Aldé (UERJ)

Vice-Presidente: Luis Felipe Miguel (UnB)

Secretário Executivo: Francisco Jamil Marques (UFC)

Editora-Chefe:

Alessandra Aldé (UERJ)

Editores Executivos:

Edna Miola (UFS) e Viktor Chagas (UFF)

Editores Assistentes:

Eleonora Magalhães (UFF) e Fernanda Sanglard (UERJ)
A Revista Compolítica é uma revista eletrônica da Associação Brasileira de

Pesquisadores em Comunicação e Política. Com periodicidade semestral, sua proposta é difundir a produção acadêmica relacionada às interfaces desses campos de estudo.

Ao citar este artigo, utilize a seguinte referência bibliográfica

ROSSETTO, Graça; CARREIRA, Rodrigo; ALMADA, Maria Paula. Twitter e comunicação política: limites e possibilidades. In: Revista Compolítica, n. 3, vol. 2, ed. julho-dezembro, ano 2013. Rio de Janeiro: Compolítica, 2013. 